\title{
APLICAÇÃO FOLIAR DE FUNGICIDAS E PRODUTOS ALTERNATIVOS REDUZ A SEVERIDADE DO OÍDIO DO TOMATEIRO
}

\author{
MORAES, Wanderson Bucker ${ }^{1,2}$ \\ JESUS JUNIOR, Waldir Cintra de $\mathrm{e}^{1,3}$ \\ BELAN, Leônidas Leoni ${ }^{1}$ \\ PEIXOTO, Leonardo de Azevedo ${ }^{1}$ \\ PEREIRA, Amilton José ${ }^{1}$
}

Recebido em: 2011-02-26

Aprovado em: 2011-09-14

ISSUE DOI: $10.3738 / 1982.2278 .554$

\begin{abstract}
RESUMO: Neste trabalho foi avaliado o efeito aplicação de fungicidas (protetor e sistêmico) e produtos alternativos na redução da severidade de oídio em folhas de tomate em condições controladas. O experimento foi conduzido em delineamento inteiramente casualizado, com cinco repetições e dez tratamentos (T), a saber: T1 água destilada; T2 - tebuconazole; T3 - oxicloreto de cobre; T4 - silicato de potássio; T5 - acibenzolar-s-metil; T6 - fosfito de cobre; T7 - calda Viçosa; T8 - extrato de óleo de nim; T9 - extrato alcoólico de própolis; T10 urina de vaca. Houve efeito da aplicação de fungicidas e produtos alternativos sobre a severidade do oídio do tomateiro. Os maiores valores de severidade da doença foram observados em plantas que receberam aplicações de água destilada. Todos os produtos avaliados foram eficientes em controlar o oídio do tomateiro. Entre os fungicidas avaliados, o fungicida sistêmico (tebuconazole) foi mais eficiente que o fungicida protetor (oxicloreto de cobre). O efeito da aplicação de tebuconazole, silicato de potássio, calda Viçosa e extrato alcoólico de própolis apresentaram maior eficiência quando comparado com os demais tratamentos. Portanto, o efeito destes produtos alternativos teve a mesma eficiência do fungicida sistêmico (tebuconazole). Assim, o uso de produtos alternativos é uma medida promissora a ser integrada no manejo do oídio do tomateiro.
\end{abstract}

Palavras-chave: Solanum lycopersicum. Oidium spp. Controle químico. Indução de resistência. Nutrição mineral

\section{FOLIAR APPLICATION OF FUNGICIDES AND ALTERNATIVE PRODUCT REDUCES THE SEVERITY OF POWDERY MILDEW OF TOMATO}

SUMMARY: This study evaluated the effect of fungicide application (protective and systemic) and alternative products in reducing the severity of powdery mildew on tomato leaves under controlled conditions. The experiment was conducted in a randomized design with five replications and ten treatments (T): T1 distilled water, T2 - tebuconazole, T3 - copper oxychloride, T4 - potassium silicate, T5 - acibenzolar-s-methyl T6 - phosphite copper T7 - Viçosa syrup,T8 - extract of neem oil, T9 - extract of propolis; T10 - cow urine. There was a significant effect of the application of fungicides and alternative products on the severity of powdery mildew of tomato. The highest values of disease severity were observed inplants that received injections of distilled water. All products were effective the control of powdery mildew of tomato. Among the fungicides, systemic fungicide (tebuconazole) was more efficient than the protectant fungicide (copper oxychloride). The effect of tebuconazole, potassium silicate, Viçosa syrup and extract of propolis showed higher

\footnotetext{
${ }^{1}$ Universidade Federal do Espírito Santo, Centro de Ciência Agrarias, Departamento de produção vegetal, , Alto universitário s/n, 29500-000, Alegre, ES, Brasil. E-mail: wbucker@yahoo.com.br; wcintra@cca.ufes.br; leonidas_agronomia@yahoo.com.br; leonardopeixotoagro@hotmail.com; amilton.mf@hotmail.com

${ }^{2}$ Bolsista de Iniciação Científica do $\mathrm{CNPq}$

${ }^{3}$ Bolsista de Produtividade em Pesquisa do CNPq
} 
efficiency when compared with other treatments. Therefore, the effect of these alternative products had the same efficiency of systemic fungicide (tebuconazole). Thus, the use of alternative products is a promising alternative to be integrated in the management of powdery mildew of tomato.

Keywords: Solanum lycopersicum. Oidium spp. Chemical control. Induced resistance. Mineral nutrition.

\section{INTRODUÇÃO}

A cultura do tomate ocupa o segundo lugar em ordem de importância econômica dentre as culturas oleráceas no Brasil (SANTINI, 2001). A importância do tomate pode ser atribuída a sua múltipla forma de consumo, podendo ser empregada "in natura" ou como extratos industriais. O Brasil atualmente está entre os dez maiores produtores de tomate (Solanum lycopersicum) do mundo (FAO-FAOSTAT, 2011).

No entanto, a produção de tomate no Brasil é limitada por vários fatores, sendo as doenças um dos principais problemas. O cultivo do tomate está sujeito ao ataque de inúmeros patógenos, dentre estes se tem o oídio (Oidium spp.). Apesar do oídio não ser uma das doenças mais destrutivas que acomete esta cultura, sua importância relativa tem merecido maior atenção com aumentado do cultivo do tomateiro em condições de campo aberto no Centro Oeste e Nordeste do país (REIS et. al., 2005). Adicionalmente, sua importância é alta em lavouras sob cultivo protegido (estufas), onde a desfolha precoce provocada pelo patógeno pode ocasionar perdas de até 40\% (COSTA; VENTURA, 2010).

O elevado número de doenças que reduzem ou até mesmo impedem a produção do tomateiro impulsionam o uso intensivo de grandes quantidades de agroquímicos (BARRETO; SCALOPPI, 2000). Entretanto, atualmente não há produtos fitossanitários registrados para o manejo do oídio em tomate (MAPA, 2011). A resistência genética é um método de manejo eficaz para controle do oídio. Porém seu uso é restrito, uma vez que nem sempre é possível conciliar cultivares resistente e características agronômicas desejáveis (DOUGLAS, 2010). Portanto o manejo do oídio do tomateiro com produtos alternativos apresenta-se como uma medida promissora, visando buscar métodos de manejo com menor impacto ao meio ambiente e ao consumidor.

Entre estes produtos, a utilização de Si vem revelando ser uma alternativa promissora no manejo de doenças de plantas. O silício ( $\mathrm{Si}$ ), embora não seja essencial às plantas, é considerado como um elemento benéfico, pois promove o desenvolvimento de muitas espécies de monocotiledôneas como arroz, cana-de-açúcar e cereais de inverno. Resultados de pesquisa têm confirmado efeito positivo do silício na redução da severidade de várias doenças Nucleus, v.8, n.2, out.2011 
tanto em monocotiledôneas quanto em dicotiledôneas (DATNOFF et al., 2007). Além da utilização do $\mathrm{Si}$, outros produtos alternativos vendo sendo reconhecidos por ser efetivos em reduzir a intensidade de doenças de plantas. Várias substâncias químicas e extratos com suposta atividade indutora são citados, incluindo vários sais inorgânicos, oxalato, fosfato, 2thiouracil, ácido poliacrílico (STEIN; LOEBENSTEIN, 1972; ANTONIW; WHITE, 1980). Adicionalmente, a urina de vaca também tem sido empregado no manejo de algumas doenças de plantas (BROEK et al., 2002; BELAN et al., 2010), além de ser empregada como fertilizante em culturas agronômicas (FERNANDES, 2000).

Portanto, dada a importância do oídio para o cultivo do tomate especialmente em cultivos protegidos e a indisponibilidade de fungicidas registrados para este patossistema, a utilização de produtos alternativos é apresentada como uma forma promissora a ser integrada no manejo desta doença. Neste estudo, avaliamos o efeito de fungicidas (protetor e sistêmico) e produtos alternativos na redução da severidade de oídio em folhas de tomate, considerando a carência de informação dessa natureza na literatura.

\section{MATERIAIS E MÉTODOS}

O experimento foi conduzido em condições de casa de vegetação no Centro de Ciências Agrárias da Universidade Federal do Espírito Santo em Alegre - ES, no período de setembro a outubro de 2010. O delineamento experimental foi inteiramente casualizado com 5 repetições e 10 tratamentos constituídos por fungicidas e produtos alternativos. Cada unidade experimental foi composta por um vaso contendo uma planta.

\section{Cultivo do tomate e aplicação dos tratamentos}

Sementes de tomateiro 'Santa Cruz' foram semeadas em substrato contido em bandejas de isopor de 128 células. As mudas de tomate foram transplantas para vasos plásticos contendo $2 \mathrm{Kg}$ de solo (Latossolo Vermelho-Amarelo distroférrico) aos 25 dias após a semeadura, quando as plantas apresentaram cinco pares de folhas definitivas. Os tratos culturais foram realizados de acordo com as recomendações para a cultura, realizando a correção da acidez do solo e adubação (FILGUEIRA, 2003).

Os tratamentos (T) foram constituídos da aplicação de fungicidas (sistêmicos e protetores) e produtos alternativos (Tabela 1). Visando analisar somente o efeito dos produtos aplicado sobre o desenvolvimento do oídio, a testemunha utilizada foi composta por aplicação de água destilada. O extrato alcoólico de própolis utilizado neste estudo foi preparado no laboratório de Fitopatologia do CCA-UFES, na proporção de 30\% de própolis bruta (30\% i.a.) 
em álcool a $70{ }^{\circ} \mathrm{GL}$, conforme a metodologia proposta por Garcia et al. (2004) e Pereira et al. (2008). Decorridos 30 dias o extrato foi filtrado em papel filtro. Neste estudo, a própolis verde utilizada foi proveniente da região da Zona da Mata do Estado de Minas Gerais.

As aplicações dos tratamentos na parte aérea das plantas foram realizadas 30 dias após o transplantio das mudas, quando se observou o aparecimento dos primeiros sintomas da doença. Para aplicação dos tratamentos empregaram-se pulverizadores manuais.

Tabela 1. Tratamentos utilizados para o controle de oídio (Oidium spp.) em plantas de tomateiro em condição controladas.

Tratamento

Nome Técnico

1. Testemunha*

2. Tebuconazole

3. Oxicloreto de cobre

4. Silicato de potássio

5. Acibenzolar-s-metil

6. Fosfito de cobre

7. Calda Viçosa

8. Extrato de óleo de nim

9. Extrato alcoólico de própolis

10. Urina de vaca
Concentração do produto

Nome Comercial

(g ou mL.L $\left.{ }^{-1} \mathbf{H}_{2} \mathbf{O}\right)$

*Testemunha: aplicação de água destilada. **Doses de fungicida sistêmico e ***protetor recomendada para o controle de outras doenças do tomateiro.

\section{Inoculação e avaliação da intensidade da doença}

A inoculação do patógeno ocorreu de forma natural, uma vez que as plantas de tomate foram mantidas em casa-de-vegetação com alto potencial de inóculo. A intensidade do oídio foi quantificada pela avaliação da severidade da doença, realizada 15 dias após aplicação dos tratamentos. A severidade da doença foi determinada a partir de imagens obtidas via "scanner", utilizando-se do aplicativo computacional QUANT 1.0.2 (VALE et al., 2003). A terceira, quarta e quinta folha definitiva localizada acima do colo das plantas, foram destacadas para determinação da severidade da doença. Portanto, os valores de severidade de cada parcela experimental foram obtidos da severidade média das três folhas.

A avaliação da eficiência dos fungicidas e produtos alternativos no controle do oídio do tomateiro foi realizada empregando a seguinte fórmula: 


\section{Eficiência $(\%)=100$ - Severidade do tratamento $\mathrm{Y}^{*} 100$}

Severidade da testemunha

\section{Análise estatística}

Os dados de severidade da doença e eficiência dos tratamentos foram submetidos à análise de variância e as médias comparadas pelo teste de Scott-Knott a 5\% de probabilidade.

\section{RESULTADOS E DISCUSSÃO}

Aplicações de fungicidas e produtos alternativos influenciaram a severidade do oídio em plantas de tomate (Figura 1). Os maiores valores de severidade foram observados em plantas tratadas com água destilada (testemunha) $(\mathrm{P} \leq 0,05$, Figura 1). Vale ressaltar que o molhamento foliar inibe a germinação e infecção do oídio do tomateiro, sendo inclusive indicado como método de manejo para este patossistema (BUDGE, 2000). Portanto, os resultados observados nos demais tratamentos devem ser atribuídos exclusivamente ao efeito das substâncias avaliadas, e não a água empregada como veículo de distribuição dos produtos. Desta forma, tanto a aplicação de fungicidas como de produtos alternativos reduziram a intensidade da doença $(\mathrm{P} \leq 0,05$, Figura 1$)$.

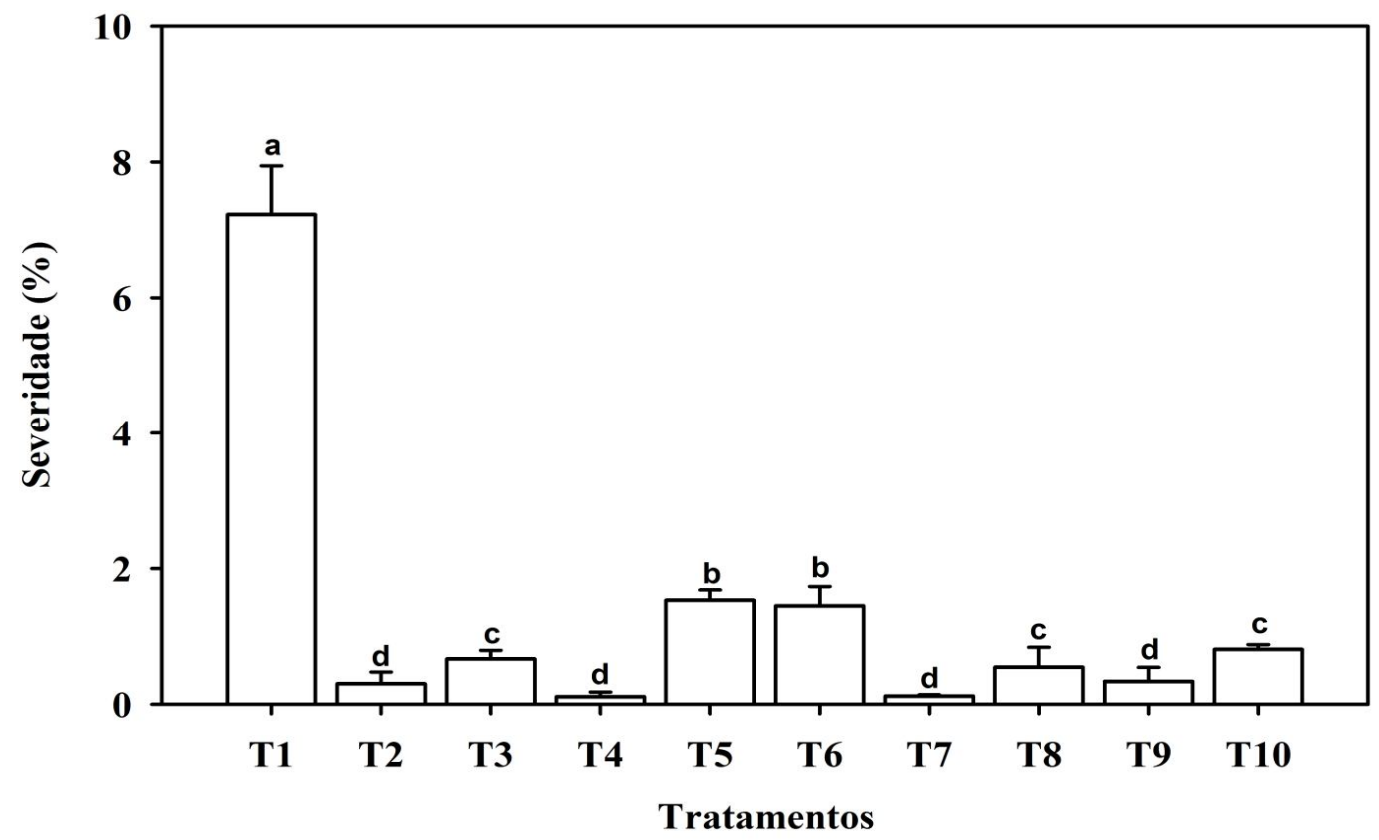

Figura 1. Efeito da aplicação de fungicidas e produtos alternativos na redução da severidade do oídio do tomateiro: T1- água destilada $\left(\mathrm{H}_{2} \mathrm{O}\right)$; T2 - tebuconazole; T3 - oxicloreto de cobre; T4 - silicato de potássio; T5 - acibenzolar-s-metil; T6 - fosfito de cobre; T7 - calda Viçosa; T8 - extrato de óleo de nim; T9 - extrato alcoólico de própolis; T10 - urina de vaca. Médias seguidas pela mesma letra não diferem entre si pelo teste de Scott-Knott, ao nível de 5\% de probabilidade. Barra vertical, em cada ponto, representa o desvio-padrão da média. 
Apesar da aplicação de fosfito de cobre e acibenzolar-s-metil ter reduzido respectivamente em 78,8 e 79,9\% a severidade do oídio em comparação a testemunha, estes tratamentos foram menos eficientes quando comparada aos demais produtos $(\mathrm{P} \leq 0,05$, Figura 2). Aplicação de acibenzolar-s-metil tem apresentado resultados promissores no manejo de doenças de plantas. Fidantsef et al. (1999) comprovaram a eficiência do acibenzolar-s-metil na redução da severidade da pinta bacteriana do tomateiro causada por Pseudomanas syringae. Estudos realizados por Anfoka (2000) comprovaram a eficácia desse produto na redução da incidência e severidade do vírus do mosaíco em tomateiro. Töfoli et al. (2005) verificaram que aplicação de acibenzolar-s-metil isolada ou associada com fungicidas em intervalos de 5 a 10 dias reduziram o progresso da requeima da batata. Silva et al. (2003) verificaram que aplicações de acibenzolar-s-metil em intervalos de sete dias resultou em proteção de $44,6 \%$ a plantas de tomate contra o oídio. Além disso, estes mesmo autores observaram que a proteção promovida por este produto reduziu a intensidade da Xanthomonas vesicatoria, Septoria lycopersici. Portanto, o uso do acibenzolar-s-metil apresenta-se como uma alternativa promissora a ser utilizado de forma complementar no manejo do oídio do tomateiro, uma vez que a resistência induzida pode contribuir para o controle de diferentes doenças do tomateiro.

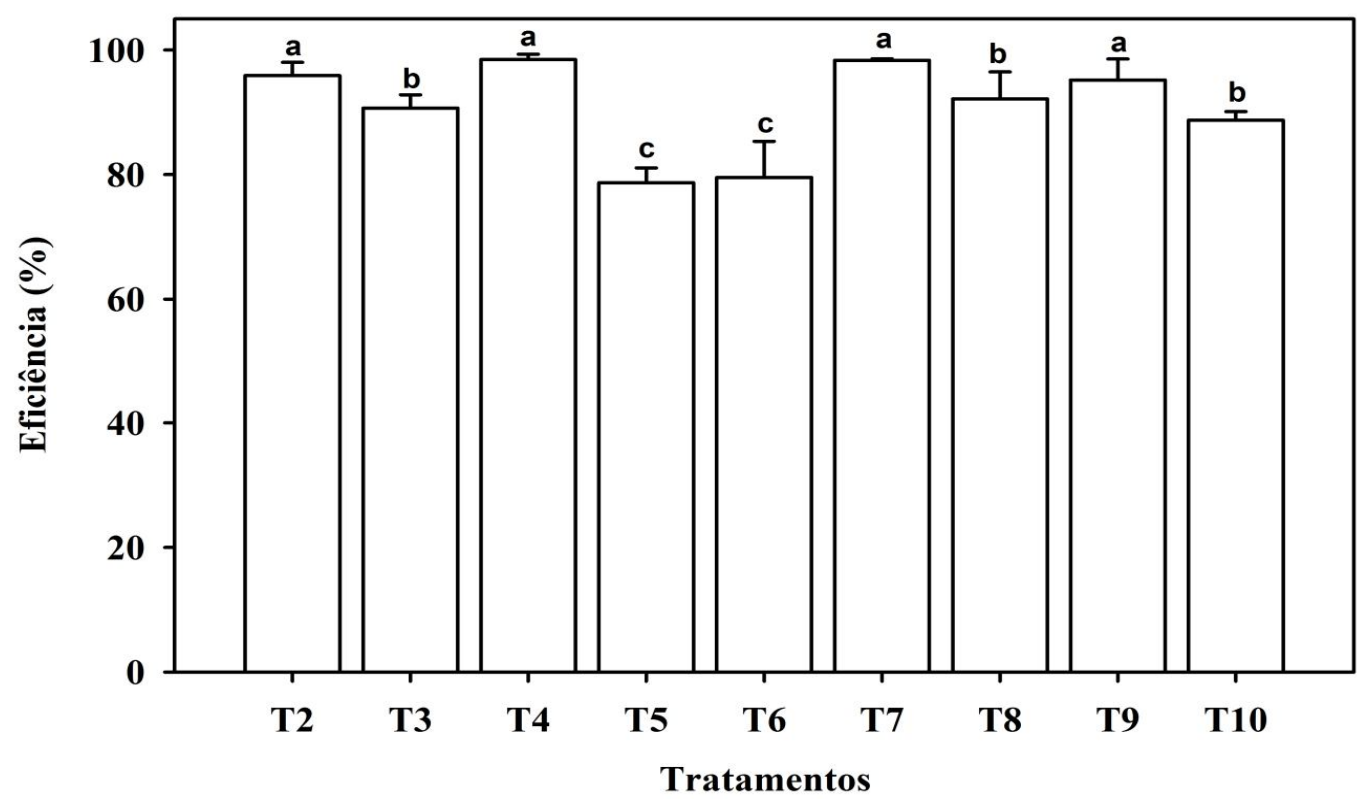

Figura 2. Eficiência da aplicação de fungicidas e produtos alternativos na redução da severidade do oídio do tomateiro: T1- água destilada $\left(\mathrm{H}_{2} 0\right)$; T2 - tebuconazole; T3 oxicloreto de cobre; T4 - silicato de potássio; T5 - acibenzolar-s-metil; T6 - fosfito de cobre; T7 - calda Viçosa; T8 - extrato de óleo de nim; T9 - extrato alcoólico de própolis; T10 urina de vaca. Médias seguidas pela mesma letra não diferem entre si pelo teste de ScottKnott, ao nível de 5\% de probabilidade. Barra vertical, em cada ponto, representa o desviopadrão da média. 
No entanto, é importante salientar que a indução de resistência da planta ao patógeno promovida pelo acibenzolar-s-metil não é duradoura. Neste trabalho realizou-se a avaliação da severidade da doença 15 dias após a aplicação deste tratamento, o que difere do intervalo de aplicações adotado por Silva et al. (2003). Portanto, há necessidade de pesquisas com intuito de identificar a duração da indução de resistência de plantas de tomate ao oídio, visando otimizar o efeito e o uso deste produto no manejo desta doença.

Com relação ao fosfito, tem-se observado a intensificação do uso deste fertilizante. Este possue ação no controle de várias doenças, principalmente fúngicas. Segundo Guest \& Grant (1991) o fosfito de potássio inibe o crescimento dos esporos dos fungos, agindo como uma toxina direta sobre o patógeno podendo ser eficiente para controlar varias espécies de Phythophora. Os fosfitos também possuem ação indireta no controle de patógenos, estimulando a formação de fitoalexinas, uma substância natural de autodefesa da planta (DERCKS; CREASY, 1989). Nascimento et al. (2008) relataram que o uso de fosfitos reduziram a severidade da $X$. campestris e a incidência de Erwinia spp. No entanto, estes autores verificaram que aplicações de fosfitos não foram eficientes no manejo da Phytophthora infestans.

O efeito da aplicação de oxicloreto de cobre (fungicida protetor), extrato de óleo de nim e urina de vaca, proporcionaram controle intermediário do oídio do tomateiro quando comparado aos demais produtos $(\mathrm{P} \leq 0,05$, Figura 1 e 2$)$. Aplicações destes tratamentos reduziram significativamente os valores de severidade do oídio, quando comparada com a testemunha, fosfito de cobre e acibenzolar-s-metil ( $\mathrm{P} \leq 0,05$, Figura 1). Os tratamentos baseados em aplicações de oxicloreto de cobre, extrato de óleo de nim e urina de vaca apresentaram eficiência de respectivamente, 98,4, 95,3 e 97,4\% no manejo do oídio do tomateiro quando comparada a testemunha (Figura 2). Portanto, apesar do oxicloreto de cobre $\left(\right.$ Recop $\left.^{\circledR}\right)$ não ser registrado para o controle do oídio do tomateiro (MAPA, 2011), o efeito deste tratamento foi eficiente em promover a proteção da cultura contra esta doença. Contudo, o extrato de óleo de nim tem sido empregado de forma eficiente no manejo de doenças de plantas sem oferecer risco ao homem e o meio ambiente. Carneiro et al. (2003) verificaram que a utilização de extrato de folhas de nim não foram eficientes no controle do oídio do tomateiro. Contrariamente, o emprego do óleo emocionável de nim controlou esta doença mesmo nas menores concentrações avaliadas e foi similar ao fungicida triforine utilizado como controle. Portanto, os resultados obtidos neste estudo corroboram com os verificados por Carneiro et al. (2003), uma vez que a eficiência obtida com aplicação de óleo de nim não diferiu do efeito do tratamento com oxicloreto de cobre ( $\mathrm{P} \leq 0,05$, Figura 2$)$. 
Com relação à urina de vaca, resultados positivos têm sido relatados com o uso de urina de vaca em diversas culturas como pepino, abacaxi, quiabo. Broek et al. (2002) avaliaram diferentes doses de urina de vaca no controle de oídio do quiabeiro, tendo verificado que a dose de $30 \%$ foi a mais eficiente no controle da doença. De acordo com estes autores, a urina de vaca é composta de $90 \%$ de água e $10 \%$ de nutrientes, sendo tanto macro como micronutrientes, fenóis e outros componentes. Belan et al. (2010) avaliaram a eficiência de diversos tratamentos para o manejo do oídio na cultura do pepino em condições de ambiente protegido. De acordo com os autores, a urina de vaca (30\% v:v) foi eficiente do controle do oídio. Estes autores também relatam que as plantas que receberam solução contendo urina de vaca produziram maior número de frutos.

A maior redução significativa da severidade do oídio do tomateiro foi observada em plantas tratadas com tebuconazole (fungicida sistêmico), silicato de potássio, calda viçosa e extrato alcoólico de própolis $(\mathrm{P} \leq 0,05$, Figura 1). Portanto, os efeitos destes tratamentos apresentaram maior eficiência no controle do oídio quando comparado aos demais produtos $(\mathrm{P} \leq 0,05$, Figura 2).

Aplicação de silicato de potássio teve 98,7\% de eficiência em relação à testemunha (Figura 2). O efeito positivo do silício na redução da severidade do oídio foi observado em várias dicotiledôneas cultivadas comercialmente. Aplicação de Si na forma de silicato de potássio e de silicato de sódio reduziu a severidade do oídio em cultivos hidropônicos de pepino (ADATIA; BESFORD, 1986). Bowen et al. (1992) observaram que a aplicação foliar de silicato de potássio reduziu significativamente a severidade de oídio em folhas de uva quando comparado a testemunha. O silício tem potencial em maximizar as respostas de defesa de plantas a patógenos foliares por meio da produção de compostos fenólicos, aumento na produção de fitoalexina e na transcrição de alguns genes que codificam proteínas relacionadas com a patogênese (DATNOFF et al., 2007). Adicionalmente, existe a formação de barreira física pela sua deposição abaixo da cutícula que afeta o processo infeccioso dos patógenos. Além da função estrutural o silício atua na ativação mais rápida e extensiva dos mecanismos de defesa, principalmente nos locais de penetração do fitopatógeno (BÉLANGER et al., 2003). Outro importante mecanismo que tem sido verificado por alguns autores é a formação de uma barreira física formada pela polimerização do silicato de potássio na superfície foliar, impedindo assim a adesão de propágulos do patógeno (BOWEN et al., 1992). Acredita-se que o silicato polimerizado na superfície das folhas influencia a infecção de patógenos pelo aumento do potencial osmótico ou pela formação de placas de silicato, após polimerização sobre a camada de cera e de cutícula (KOCH; HOPPE, 1988). 
Com relação ao efeito do extrato alcoólico de própolis, esta substância possui propriedades terapêuticas, antimicrobianas, antiinflamatórias, cicatrizantes e anestésicas (GHISALBERTI et al., 1977). Além das propriedades químicas da própolis no controle de fitopatógenos, a formação de um filme protetor sobre a planta promove um impedimento físico para a penetração dos micélios dos fungos (PEREIRA et al., 2008). Outros estudos já verificaram eficiência da própolis em diferentes patossistemas vegetais (MEDEIROS et al., 2008; PEREIRA et al., 2008). Entretanto, para a cultura do tomateiro os resultados deste estudo vêm revelar uma nova alternativa eficiente para o manejo do oídio em substituição aos fungicidas.

A calda Viçosa é outro produto que apresentou alta eficiência no manejo do oídio do tomateiro. A eficiência deste produto tem sido comprovada no manejo de outras doenças do tomateiro. Resultados experimentais sobre o controle de pinta preta do tomateiro colocam a calda Viçosa no mesmo nível de eficiência de controle do chlorothalonil (fungicida amplamente utilizado na cultura do tomate), em aplicações semanais (ANDRADE, 1997). A calda Viçosa, devido ao fato de fornecer elementos minerais (zinco, boro, cobre) e em menor intensidade (cálcio, magnésio e potássio), proporciona maior vigor às plantas e consequentemente maior produção. Portanto, plantas tratadas com calda Viçosa tem-se tornado mais tolerantes ao ataque de fungos e bactérias que incidem na parte aérea das hortaliças (ZAMBOLIM et al., 2007).

Quando comparada a eficiência dos fungicidas oxicloreto de cobre e tebucanazole, o emprego do tebucanazole apresentou maior eficiência no manejo do oídio do tomateiro (Figura 2). Vale ressaltar que o oxicloreto de cobre $\left(\right.$ Recop $^{\circledR}$ ) e tebucanazole (Folicur ${ }^{\circledR}$ ) são produtos não registrados para o controle do oídio em tomate (MAPA, 2011). No entanto, estes produtos já tiveram sua eficiência comprovada no manejo de espécies de oídio de diversas culturas de importância econômica. Assim, existe o registro desses fungicidas no Ministério da Agricultura, Pecuária e Abastecimento (MAPA) para o controle de oídio em outras culturas. Além disso, estes produtos e as doses empregadas neste trabalho são as recomendas para o manejo de outras doenças do tomateiro (MAPA, 2011). Desta forma, aplicação desses fungicidas não oferece risco de fitoxidez à cultura, bem como o acúmulo de resíduos nos frutos. Portanto a utilização desses produtos de forma integrada é uma possível alternativa a ser utilizada no manejo do oídio do tomateiro. Contudo, estudos visando a identificação de menores doses que apresentem a máxima eficiência devem ser realizados com o intuito de otimizar o emprego destes produtos e minimizar os impactos ao meio ambiente.

É importante ressaltar que tanto aplicação de fungicidas como de produtos alternativos, foram eficientes em controlar o oídio do tomateiro. Portanto, o emprego de 
produtos alternativo apresenta-se como uma medida promissora a ser empregada no controle do oídio do tomateiro de forma integrada com fungicidas e outro métodos de manejo.

\section{CONCLUSÃO}

Aplicação de fungicidas e produtos alternativos reduziu em todos os tratamentos avaliados a severidade do oídio em plantas de tomate. Os maiores valores de severidade foram observados em plantas tratadas com água destilada. O efeito da aplicação de tebuconazole, silicato de potássio, calda Viçosa e extrato alcoólico de própolis foram os tratamentos mais eficiência no controle do oídio do tomateiro. O efeito da aplicação de silicato de potássio, calda Viçosa e extrato alcoólico de própolis tiveram a mesma eficiência do fungicida sistêmico (tebuconazole). Portanto, o uso de produtos alternativos é uma medida promissora a ser integrada no manejo do oídio do tomateiro.

\section{REFERÊNCIAS}

ADATIA, M.H.; BESFORD, R.T. The Effects of Silicon on Cucumber Plants Grown in Recirculating Nutrient Solution. Annals of Botany, v.58, p.343-351, 1986.

MAPA. Agrofit - Sistema de Agrotóxicos Fitossanitários. Disponível em: $<$ http://extranet.agricultura.gov.br/agrofit_cons/principal_agrofit_cons $>$. Acesso em: $30 \mathrm{de}$ jan. 2011.

ANDRADE, D.F.A.A. Previsão e controle químico de pinta-preta (Alternaria solani) sob dois sistemas de condução do tomateiro (Lycopersicon esculentum Mill.). Viçosa, MG: UFV, 1996. 103p. Dissertação (Mestrado em Fitopatologia) - Universidade Federal de Viçosa, 1997.

ANFOKA, G.H. Benzo-(1, 2, 3)-thiadiazole-7-carbothioic acid S-methyl ester induces systemic resistance in tomato (Lycopersicon esculentum. Mill cv.Vollendung) to Cucumber mosaic virus. Crop Protection, v.19, n.6, p.401-405, 2000.

ANTONIW, W.J.; WHITE, R. The effects of aspirin and polyacrylic acid on soluble leaf proteins and resistance to virus infection in five cultivars of tobacco. Phytopathology, v.98, p.331-341, 1980.

BARRETO, M.; SCALOPPI, E.G. Sistemas de previsão de hortaliças. In: ZAMBOLIM, L. (Ed.) Manejo integrado-doenças, pragas e plantas daninhas. Viçosa MG. Suprema Gráfica e Editora, 2000. p.169-186.

BÉLANGER, R.R.; BENHAMOU, N.; MENZIES, J.G. Cytological evidence of an active role of silicon in wheat resistance to powdery mildew (Blumeria graminis f. sp. tritici).

Phytopathology, v.93, p.402-412, 2003. 
BELAN, L.L et al. Avaliação da eficiência de controles alternativos para oídio (Oidium sp.) na cultura do pepino. In: X Encontro latino americano de pós-graduação. Anais... São José dos Campos - SP. UNIVAP - Urbanova, v.1. p.1-4. 2010.

BOWEN, P. et al. Soluble silicon sprays inhibit powdery mildew development on grape leaves. Journal of the American Society for Horticultural Sciense, v.117, p.906-912, 1992.

BROEK, R.V.D. et al. Controle alternativo de oidio (Erysiphe cichoracearum) em quiabeiro (Hibiscus esculentum). Revista Ecossistema. v.27, n. 1, p. 23-26, 2002.

BUDGE, J.M.W.S.P. Effect of humidity on development of tomato powdery mildew (Oidiumlycopersici) in the glasshouse. European Journal of Plant Pathology, v.106, p.395397, 2000.

CARNEIRO, S.M.T.P.G. Efeito de extratos de folhas e do óleo de nim sobre o oídio do tomateiro. Summa Phytopathologica, v.29, n.3, p.203-213, 2003.

COSTA, H.; VENTURA, J.A. Doenças do tomateiro no Estado do Espírito Santo: Reconhecimento e manejo. In: MOLINO, J.A. et al. (Ed.) Tomate. Vitória, ES: INCAPER, 2010. p.227-314.

DATNOFF, L.E.; RODRIGUES, F.A.; SEEBOLD, K.W. Silicon and Plant Nutrition. In: DATNOFF, L.E.; ELMER, W.H.; HUBER, D.M. (Ed.) Mineral Nutrition and Plant Disease. Saint Paul MN: APS Press. p.233-246, 2007.

DERCKS, W.; CREASY, L.L. Influence of fosetyl - Al on phytoalexin accumulation in the Plasmoparaviticola-grapevine interaction. Physiologicaland Molecular PlantPathology, v.34, p.203-213, 1989.

DOUGLAS, S.M. Powdery mildew of tomato. 2003. Disponível em:

$<$ http://www.ct.gov/caes/lib/caes/documents/publications/fact_sheets/plant_pathology_and_ec ology/powdery_mildew_of_tomato.pdf>. Acesso em: 01 fev. 2010.

FAO-FAOSTAT. Database Results-2010. Disponível em http://apps.fao.org/ . Acesso em: 12 jan. 2011.

FIDANTSEF, A.L. et al. Signal interactions in pathogen and insect attack: expression of lipoxygenase, proteinase inhibitor II, and pathogenesis-related protein $\mathrm{P} 4$ in the tomato, Lycopersiconsculentum. Physiological and Molecular Plant Pathology, v.54, n.3, p.97-114, 1999.

FILGUEIRA, F.A.R. Novo manual de olericultura: agrotecnologia moderna na produção e comercialização de hortaliças. 2. ed. Viçosa: UFV, 2003. 409p.

GARCIA, R.C. et al. Efeito do Extrato Alcoólico de Própolis sobre a Pasteurella multocida " in vitro" e em Coelhos. Acta Scientiarum Animal Sciences, Maringá, v. 26, n. 1, p. 69-77, 2004.

GHISALBERT, I.E.L.; JEFFERIES, P.R.; LANTERI, R. Potencial drugs from própolis. In: FRIGERIO, A.; GHISALBERTI, E.L. (Ed.). Mass spectrometry in drugs metabolism. New York, Plenum Press, p.111-130. 1977.

GUEST, D.; GRANT, B.R. The complex action of phosphonates as antifungal agents.

Biological Reviews, v.66, p.159-187. 1991. 
KOCH, E.; HOPPE, H.H. Development of infection structures by the direct-penetrating soybean rust fungus (PhakopsorapachyrhiziSyd.) on artificial membranes. Journal of Phytopathology, v.122, p.232-244, 1988.

MEDEIROS, C.A.B. et al. Controle alternativo de requeima (Phytophthorainfestans) em batata cultivada em sistema de base ecológica. Horticultura Brasileira, v.26, 2008.

NASCIMENTO, A.R. et al. Fontes de fosfito e acibenzolar-s-metil no controle de doenças e produtividade do tomateiro. Bioscience Journal, v.24, n.1, p.53-59, 2008.

PEREIRA, C.S. et al. Controle da cercosporiose e da ferrugem do cafeeiro com extrato etanólico de própolis. Revista Ceres, v.55, n.5, p.369-376, 2008.

PEREIRA, A.S.; SEIXAS, F.R.M.S.; AQUINO NETO, F.R. Própolis: 100 anos de pesquisa e suas perspectivas futuras. Quimica Nova, v.25, n.2, p.321-326, 2002.

REIS, A.et al. Oidiopsis haplophilly (Leveilula taurica); um patógeno polifago e amplamente distribuído no Brasil. Comunicado técnico, v.26, p.1-13, 2005.

SANTINI, A. Tomate: manejo de pragas e doenças. Correio Agrícola, v.2, p.8-11, 2001.

SILVA, L.H.C.P. et al. Efeito doindutor de resistênciaacibenzolar-S-methyl na proteção contra Xanthomonas vesicatoria, Oidium lycopersicie Septoria lycopersici em tomateiro. Summa Phytopathologica, v.29, n.3, p.244-248, 2003.

STEIN, A.; LOEBENSTEIN, G. Induced interference by synthetic polyanions with the infection of tobacco mosaic virus. Phytopathology, v.62, p.1461-1466, 1972.

TÖFOLI, J.G. et al. Ação de acibenzolar-s-methyl isolado e em mistura com fungicidas no controle da requeima da batata. Horticultura Brasileira, v.23, n.3, p.749-753, 2005.

VALE, F.X.R., FERNANDES FILHO, E.I.; LIBERATO, J.R. QUANT, a software plant disease severity assessment. In: INTERNATIONAL CONGRESS OF PLANT PATHOLOGY, 8. Christchurch New Zealand, 2003. p.105.

ZAMBOLIM, L.; COSTA, H.; JESUS JUNIOR, W.C. Manejo integrado das doenças das hortaliças. In: ZAMBOLIM, L. et al. (Org.). Manejo integrado de doenças e pragas em hortaliças. Visconde do Rio Branco: Suprema, 2007, v.1, p.225-318. 